\title{
Infección por Herpes virus Humano tipo 6 relacionado con manifestaciones dermatológicas y fatiga crónica: serie de casos
}

\author{
Gloria Inés Ávila-González1* orcid.org/0000-0002-4133-6980 \\ Andrés Felipe Erazo-Narváez ${ }^{1}$ orcid.org/0000-0003-0545-4848 \\ Fernando Sánchez-Muñoz' orcid.org/0000-0002-7205-6172 \\ Rigobert Alexis Riascos-Montes' ${ }^{1}$ orcid.org/0000-0001-8597-4688 \\ Cristian Anacona ${ }^{1}$ orcid.org/0000-0001-9176-939X \\ Rosa Amalia Dueñas-Cuellar1 orcid.org/0000-0002-2157-1131 \\ Victoria Eugenia Niño-Castaño1 orcid.org/0000-0002-7726-3613 \\ Julio César Klínger1 orcid.org/0000-0001-9595-4445
}

Human Herpesvirus type 6 infection related to dermatological manifestations and chronic fatigue: case series

1. Grupo de Investigación en Inmunología y Enfermedades Infecciosas, Departamento de Patología, Facultad de Ciencias de la Salud, Universidad del Cauca. Popayán, Colombia

Fecha de recepción: Noviembre 25 - 2019 Fecha de revisión: Septiembre 2 - $2019 \quad$ Fecha de aceptación: Diciembre 29 - 2020

Ávila-González GI, Erazo-Narváez AF, Sánchez-Muñoz F, Riascos-Montes RA, Anacona C, Dueñas-Cuellar RA, Niño-Castaño VE, Klínger JC. Infección por Herpes virus Humano tipo 6 relacionado con manifestaciones dermatológicas y fatiga crónica: serie de casos. Univ. Salud. 2021;23(1):64-70. DOI: https://doi.org/10.22267/rus.212301.215

\section{Resumen}

Introducción: Las manifestaciones clínicas más frecuentes causadas por el Herpes Virus Humano Tipo 6 (HHV-6) ocurren en niños menores de 2 años, presentan lesiones en piel tipo roséola o exantema súbito. En adultos, las manifestaciones clínicas relacionadas a HHV-6 son muy variables, y pueden sobreponerse con otras afecciones. Objetivo: Presentar una serie de casos de pacientes diagnosticados con infección activa por HHV-6, quienes mostraban manifestaciones neurológicas, dermatológicas y de fatiga crónica. Materiales y métodos: Se realizó análisis de historias clínicas de 6 pacientes que fueron diagnosticados con infección activa por HHV-6, a través de métodos moleculares. Resultados: Se reportan 6 pacientes que fueron diagnosticados con infección activa por HHV-6 mediante métodos moleculares, quienes presentaron manifestaciones clínicas comunes tales como: fiebre, cefalea, depresión, decaimiento, pérdida de memoria y concentración, dolor fibromuscular, dolor poliarticular, sueño no reparador, exantema, nevus rubí, liquen plano y parestesias. Conclusiones: A través de esta serie de casos se espera resaltar la importancia de identificar la infección activa por HHV-6 a través de métodos moleculares, y sensibilizar a la comunidad médica sobre el papel que juega el virus en la evolución de diversas patologías.

Palabras clave: Herpes virus humano 6; enfermedades de la piel; síndrome de fatiga crónica; carga viral. (Fuente: DeCS, Bireme).

\begin{abstract}
Introduction: The most frequent clinical manifestations of Human Herpesvirus 6 (HHV-6) in children under 2 years of age are roseola-like skin lesions and sudden rash. In adults, the clinical manifestations associated with HHV-6 are highly variable and can overlap with other conditions. Objective: To present a case series of patients diagnosed with active HHV-6 infection, who showed neurological, dermatological and chronic fatigue manifestations. Materials and methods: An analysis of medical records of 6 patients who were diagnosed with active HHV-6 infection through molecular methods was performed. Results: 6 patients were diagnosed with active HHV-6 infection using molecular methods, who had common clinical manifestations such as fever, headache, depression, tiredness, loss of memory and concentration, fibromuscular pain, polyarticular pain, nonrestorative sleep, rash, ruby nevus, lichen planus and paresthesia. Conclusions: This case series highlights the importance of identifying active HHV-6 infection through molecular methods and creating awareness in the medical community of the role that the virus plays on the development of diverse pathologies.
\end{abstract}

Keywords: Human herpesvirus 6; skin diseases; chronic fatigue syndrome; viral load. (Source: DeCS, Bireme).

\footnotetext{
*Autor de correspondencia

Gloria Inés Ávila González

e-mail: giavila@unicauca.edu.co
} 


\section{Introducción}

El Herpesvirus humano tipo 6 (HHV-6) es miembro de la familia Herpesviridae y subfamilia Betaherpesviridae; estudios seroepidemiológicos demuestran que el HHV-6 es adquirido en edades tempranas (alrededor de los 2-3 años de edad), presenta una elevada prevalencia en la población y se estima que un porcentaje mayor al $95 \%$ de los adultos a nivel mundial se encuentran infectados(1). En Colombia, la estadística respecto a la prevalencia del HHV-6 es desconocida, este virus se caracteriza por permanecer latente después de la primoinfección, ya que tiene la capacidad de integrarse al genoma humano(2), lo que implica que la persona infectada es susceptible de desarrollar reactivación viral o co-reactivación con diferentes virus, por ejemplo, durante un evento de inmunosupresión o de estrés agudo intenso o crónico ${ }^{(1)}$.

Las manifestaciones clínicas más frecuentes causadas por el HHV-6 ocurren en niños menores de 2 años, de los cuales cerca al 90\% presentan lesiones en piel tipo roséola o exantema súbito. En adultos, las manifestaciones clínicas relacionadas a HHV-6 son muy variables y pueden sobreponerse con otras afecciones. Entre ellas, pueden relacionarse patologías dermatológicas como la pitiriasis rosácea, liquen plano, Síndrome de Stevens-Johnson, púrpura trombocitopénica, púrpura fulminante, síndrome papular purpúrico en "guante y calcetín", síndrome de Gianotti-Crosti y síndrome de hipersensibilidad a medicamentos(3). Por otro lado, se ha reportado que la infección/reactivación del HHV-6 participa como uno de los factores de patogénesis multifactorial que puede desencadenar el desarrollo de diversas patologías neurológicas como esclerosis múltiple ${ }^{(4)}$, epilepsia(5) y síndrome de fatiga crónica(6).

Dado que la infección por HHV-6 cursa con afecciones dermatológicas y neurológicas(3-5), en varias ocasiones el proceso infeccioso no es diagnosticado(1); por lo tanto, el estado de salud del paciente puede empeorar, dejando graves secuelas en su sistema inmunológico e incluso desencadenar la muerte ${ }^{(1)}$. Para diagnosticar una infección activa por HHV-6 se recomienda el uso de qPCR (Reacción en cadena de la polimerasa - cuantitativa o en tiempo real) en plasma o suero,
Inmunofluorescencia, Inmunohistoquímica y anticuerpos $\operatorname{IgM}(1)$. No obstante, la utilización de estas técnicas diagnósticas es poco frecuente en la comunidad médica y no es ofertada en la mayoría de los laboratorios clínicos colombianos. Teniendo en cuenta la importancia de la infección por el virus HHV-6 y los compromisos clínicos que este causa, el presente artículo tiene como objetivo presentar una serie de casos de pacientes diagnosticados con infección activa por HHV-6 quienes presentaban manifestaciones neurológicas, dermatológicas y de fatiga crónica.

\section{Presentación de casos}

\section{Caso 1}

Paciente masculino de 25 años, mestizo, procedente de Popayán (Cauca), con antecedentes de cáncer gástrico satisfactoriamente tratado, depresión tratada farmacológicamente, asma y distrofia miotónica inflamatoria. Al interrogatorio refiere presencia de fiebre, cefalea, asociado a odinofagia, xerostomía, úlceras a nivel oral a repetición, con presencia de emesis y episodios diarreicos en varias ocasiones, con pérdida de peso, dolor fibromuscular generalizado, dolor articular a nivel de rodillas, articulaciones metacarpofalángicas y articulación del codo. Presenta síntomas a nivel de afecto como depresión y decaimiento, refiere problemas de concentración y de memoria, sueño no reparador, malestar post esfuerzo, que el médico tratante relaciona con el síndrome de fatiga crónica. Refiere presencia de lesiones en piel tipo nevus rubí, lesiones hiperpigmentadas, lesiones lineales hipopigmentadas tipo estrías y parestesias (Figura 1A). Todo lo anteriores signos y síntomas, presentes hace aproximadamente 7 años.

El paciente ha recibido manejo médico por múltiples especialidades entre ellas, genética humana, medicina interna, gastroenterología, nefrología, cardiología y fisioterapia. Se le ordenan pruebas de laboratorio como ELISA (Enzyme-Linked ImmunoSorbent Assay) para VIH (Virus inmunodeficiencia humana), anticuerpos IgG para HHV-6, carga viral por qPCR en plasma para HHV-5, 6 y 7 y Test de Tzanck en orina. Los resultados de laboratorio descartaron infección por VIH y otros tipos de virus, mostrando infección por HHV-6 (Tabla 1). 


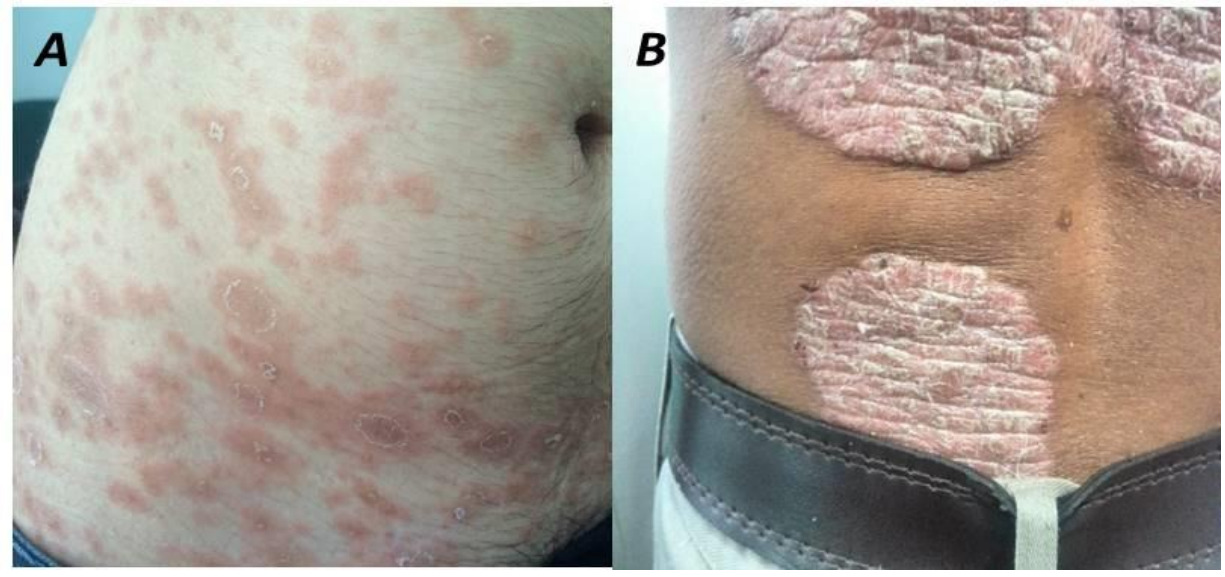

Figura 1. Manifestaciones dermatológicas: A. Caso 1: Paciente con lesiones tipo manchas rojizas localizadas en región de abdomen, con centro descamativo, confluyentes. B. Caso 4: Lesiones tipo liquenoides, costrosas hipertróficas, descamativas, bordes definidos, localizados en región lumbar.

Tabla 1. Resumen de resultados de laboratorio de los 6 pacientes estudiados con infección activa por HHV-6 de la ciudad de Popayán, 2017

\begin{tabular}{|c|c|c|c|c|c|c|c|}
\hline \multirow[b]{2}{*}{ Prueba } & \multicolumn{6}{|c|}{ Casos } & \multirow[b]{2}{*}{ Valor de referencia } \\
\hline & 1 & 2 & 3 & 4 & 5 & 6 & \\
\hline $\begin{array}{l}\text { AC anti } \\
\text { VIH 1v? }\end{array}$ & 0,35 & 0,38 & 0,38 & 0,4 & 0,29 & 0,3 & Pos $>1,1$ \\
\hline $\mathrm{AC}$ IgG & 324 & 210 & 408 & 48 & 292 & 291 & $\begin{array}{l}\text { Neg }<0,9 \\
\text { Pos }>110\end{array}$ \\
\hline Anti-HHV-6 & & & & & & & Neg $<90$ \\
\hline TT & Neg & Pos & Neg & Pos & Neg & Pos & NA \\
\hline CV HHV-5 & Ind & Ind & Ind & Ind & Ind & Ind & $\begin{array}{r}\text { Pos }>410 \\
\text { Neg }<10\end{array}$ \\
\hline CV HHV-6 & 17409 & 97307 & 110242 & 10121 & 761 & 10484,973 & $\begin{array}{r}\text { Pos }>500 \\
\text { Neg }<10\end{array}$ \\
\hline CV HHV-7 & Ind & Ind & Ind & Ind & Ind & Ind & $\begin{array}{r}\text { Pos }>500 \\
\text { Neg }<10\end{array}$ \\
\hline
\end{tabular}

CV: Carga viral (qPCR, unidad: copias/ml de ADN viral).

Ind: Indetectable. Neg: Negativo.

Pos: Positivo.

Ac: Anticuerpo.

\section{Caso 2}

Paciente masculino de 74 años, mestizo, procedente de Popayán (Cauca), ingeniero civil, con antecedentes personales de neoplasia prostática. Al interrogatorio refiere presencia de fiebre, cefalea en región occipital, odinofagia, xerostomía, xeroftalmia, decaimiento generalizado, con problemas de memoria y concentración, dolor fibromusucular generalizado, dolor articular múltiple secundario a osteoartrosis, sueño no reparador. Al examen físico se observa múltiples lesiones en piel de aproximadamente $3 \times 4 \mathrm{~cm}$ en región dorsal, de características hipopigmentadas e hiperpigmentadas como secuelas de liquen plano activo, nevus rubí en toda la región del tronco. Los resultados de laboratorio descartan infección por VIH y otros virus herpes, mostrando infección por HHV-6 mediante anticuerpos IgG, carga viral por qPCR y Test de Tzanck positivo (Tabla 1) (Figura 2A).

\section{Caso 3}

Paciente femenina de 79 años, mestiza, procedente de Popayán (Cauca), ama de casa, con antecedente de hipertensión arterial. Refiere en los últimos 6 meses odinofagia, múltiples episodios eméticos, hiporexia, cefalea, presencia de úlceras a nivel bucal, depresión y decaimiento, además de problemas de memoria y concentración, afirma presentar dolor fibromuscular generalizado, dolor articular múltiple, presencia de sueño no reparador, malestar post 
esfuerzo, cansancio crónico, refiere presentar irritación ocular en repetidas ocasiones y parestesias en miembros superiores e inferiores tipo calambre, asociado a prurito generalizado, cuadro con el que ha persistido durante 20 años consecutivos. Al examen físico se observa nevus rubí, lesiones en piel hiperpigmentadas de coloración rojizas especialmente en miembros superiores y tórax, en peores condiciones en región de codos y axilas. Región facial con presencia de micro nódulos múltiples cafés, confluentes, descamativos y uñas liqueniformes. Los resultados de laboratorio: anticuerpos IgG, carga viral por qPCR y Test de Tzanck, muestran infección HHV- 6 (Tabla 1).

\section{Caso 4}

Paciente masculino de 33 años, mestizo, procedente de Popayán (Cauca), abogado, con antecedente de bronquitis alérgica, psoriasis y dermatitis, recibió manejo con ciclosporina $A$ un año previo a la consulta. Refiere que en los últimos 6 meses ha presentado odinofagia, episodios diarreicos múltiples, hiporexia, pérdida de peso, depresión, decaimiento, problemas de memoria y concentración, presencia de nódulos linfáticos a nivel axilar, sueño no reparador, lesiones en piel tipo exantema y nevus rubí, liquen plano, irritación ocular espontánea, dolor ocular recurrente, parestesias en todo el cuerpo, prurito generalizado, psoriasis con evolución tórpida y tendencia al empeoramiento, cuadro que ha persistido durante aproximadamente 4 años. Al examen físico el paciente presenta lesiones psoriásicas complejas, múltiples nevus rubí y liquen plano. Se observa hirsutismo, a nivel de oído se observa neoangiogénesis, presencia de adenopatías occipitales, eritema y ulceraciones en surco anal, presenta además de ello lesiones tipo liquen plano en región lumbar (Figura 1B). Los resultados de laboratorio muestran anticuerpos IgG negativos para HHV-6, sin embargo, tanto la carga viral por qPCR para HHV-6 como el test de Tzanck resultan positivos (Figura 2B) (Tabla 1).

\section{Caso 5}

Paciente femenina de 50 años, mestiza, procedente de Popayán (Cauca), docente, sin antecedentes personales relevantes. Refiere que en últimos 6 meses ha presentado fiebre, cefalea, odinofagia, múltiples episodios eméticos y diarreicos, pérdida de peso, hiporexia, trastornos de memoria, dolor fibromuscular generalizado al igual que dolor articular múltiple, acompañado de sueño no reparador. Al examen físico sin alteraciones a nivel dermatológico. Los resultados de laboratorio muestran anticuerpos tipo IgG y carga viral por qPCR para HVH-6 positivos (Tabla 1 ).

\section{Caso 6}

Paciente masculino de 67 años, mestizo, procedente de Popayán (Cauca), pintor, sin antecedentes personales relevantes. Refiere en los últimos 6 meses presencia de múltiples episodios eméticos y diarreicos, sensación de decaimiento, problemas de memoria y concentración, dolor fibromuscular asociado a manifestaciones cutáneas como pápulas y puntos rubí, a nivel ocular, el paciente refiere presentar irritación en varias ocasiones, además de presentar parestesias tipo prurito en región de areola. Al examen físico presencia de alteraciones dermatológicas tipo lunares rojos y puntos rubíes en región de tórax y región dorsal generalizados. Los exámenes de laboratorio muestran anticuerpos IgG contra HHV 6 positivos, carga viral por qPCR para HVH 6 positivo y test de Tzanck positivo (Figura 2C) (Tabla 1).

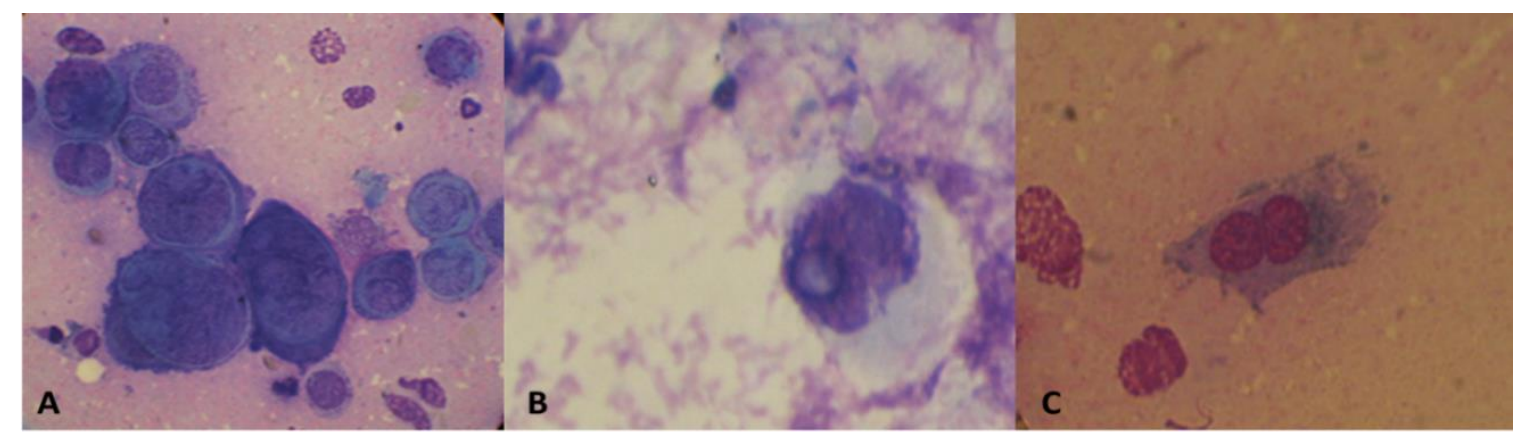

Figura 2. Test de Tzanck realizado en frotis de sedimento urinario de pacientes seropositivos para infección por HHV-6. Se observan células gigantes binucleadas y multinucleadas, núcleos con cambios megaloblásticos y cromatinas desplazadas. A. Caso 2, B. Caso 4, C. Caso 6 (imágenes observadas a 100X), diagnóstico realizado en el Laboratorio de Inmunología de la Universidad del Cauca. Fuente: propia del autor. 
En resumen, esta serie de casos reporta 6 pacientes a quienes se les diagnosticó infección activa por HHV6 a través de análisis de laboratorio clínico como carga viral por qPCR y test de Tzanck; adicionalmente se les realizó ELISA para anticuerpos tipo IgG. Entre los pacientes se identificó que la fatiga crónica y la presencia de lesiones dermatológicas fueron las manifestaciones más frecuentes. Se identificaron 4 grupos de manifestaciones clínicas clasificadas en: generales, síntomas neurológicos, fatiga crónica y dermatológicas (Tabla 2).

Tabla 2. Manifestaciones clínicas asociadas a la infección activa por HHV-6 en seis pacientes estudiados

\begin{tabular}{llll}
\hline \multicolumn{1}{c}{ Manifestaciones Generales } & Síntomas Neurológicos & Fatiga Crónica & Síntomas dermatológicos \\
\hline Fiebre & Depresión & Dolor Fibromuscular & Exantema \\
Cefalea & Decaimiento & Dolor Poliarticular & Roséola \\
Odinofagia & Pérdida de memoria & Sueño No Rapador & Vesículas \\
Dolor Ocular & Perdida de concentración & Malestar post esfuerzo & Pápulas \\
Xerostomía y Xeroftalmia & Fotofobia & & Nevus Rubí \\
Ulceras Orales & & Liquen Plano \\
Emesis & & Parestesias \\
Diarrea & & Hiperqueratosis \\
Hiporexia & & Lesiones Sebáceas \\
Irritación Ocular & & Hiper e Hipo Pigmentación \\
Adenopatías & & Telangiectasias \\
& & Exantema \\
\end{tabular}

\section{Consideraciones éticas}

Los pacientes en esta serie de casos firmaron consentimiento informado donde autorizaron el uso de la información consignada de sus historias clínicas, uso de las fotografías de lesiones dermatológicas y toma de la muestra de sangre para la realización de las pruebas para identificar la infección por HHV-6. Estos procedimientos fueron aprobados por el comité de ética de la Universidad del Cauca, según consta en el acta № 6 de 8 de junio 2016.

\section{Discusión}

Este artículo tuvo como objetivo reportar una serie de casos de pacientes diagnosticados con infección activa por HHV-6 quienes presentaban manifestaciones neurológicas, dermatológicas y de fatiga crónica. Debido a la elevada seroprevalencia, y a que el HHV-6 es persistente en células por las cuales tiene tropismo, después de la primoinfección, existe dificultad en la capacidad de diferenciar la infección activa de una latente, lo que se puede resolver con la elección de una técnica diagnóstica adecuada(7). En la actualidad el diagnóstico de infección por HHV-6 se basa en pruebas de laboratorio y moleculares que permiten detectar la presencia del mismo; qPCR, qPCR Transcriptasa Reversa de mARN (Ácido ribonucleico mensajero), el ensayo inmunoenzimático (ELISA) para anticuerpos IgM e IgG, cultivos celulares, Inmunofluorescencia (IFI) y Test de Tzanck, estos han demostrado sensibilidad y especificidad adecuada, además de rapidez para detectar la infección activa y latente(1). En este sentido, la qPCR realizada en estos pacientes estudiados amplifica secuencias específicas del genoma del HHV-6, lo que permitió determinar la presencia y cantidad del virus en las muestras de suero. De manera adicional, se cuantificó la carga viral de HHV-5 y HHV-7 en búsqueda de coinfecciones, todos los pacientes resultaron negativos.

Se ha demostrado que el $1 \%$ de la población tiene una copia del genoma de HHV-6 integrado cromosómicamente en cada célula nucleada, por lo tanto, en estas personas se puede encontrar $>5.5$ $\log _{10}$ copias/ml del virus en leucocitos(1). Por tal motivo, para diferenciar el HHV-6 integrado cromosómicamente, de una infección activa, se escogió realizar la identificación de la carga viral de los pacientes en muestras de suero, que al igual que el plasma ha mostrado ser eficiente para este tipo de identificación. En este estudio de casos, el HHV-6 estuvo presente en la totalidad de los pacientes, los cuales presentaron carga viral con un rango de 761 10484973 copias/ml de suero. Estos resultados coinciden por los reportado por Caserta et al.,(8) que muestran que la detección de ADN de HHV-6 en plasma fue positiva en un $92 \%$ de pacientes con infección activa, comparado con el 5,6\% de personas 
con HHV-6 integrado al cromosoma cuyos resultados en plasma fueron positivos.

Dentro de los casos analizados, 5 fueron positivos para anticuerpos IgG contra HHV-6 y tan solo 1 se encontró en el rango de negatividad (caso 4). Este resultado puede explicarse por el uso de ciclosporina A, el cual es un inhibidor potente de la proliferación de los linfocitos $\mathrm{T}$ auxiliares y de manera secundaria de linfocitos B timo-dependientes, los cuales necesitan la colaboración de células $\mathrm{T}$ para generar anticuerpos ${ }^{(9)}$. Existe controversia con respecto de la identificación de la infección activa por HHV-6 mediante el uso de inmunoglobulinas IgM e IgG, debido a la especificidad de los anticuerpos disponibles a nivel comercial, en particular, se ha descrito la dificultad para interpretar presencia de IgM y la reactividad cruzada que a veces se observa entre distintos betaherpesvirus ${ }^{(10)}$.

Para la descripción del presente reporte no se encontró disponibilidad de anticuerpo IgM a nivel comercial; sin embargo, como ya se mencionó este marcador tiene una utilidad limitada en infecciones activas, y se ha mostrado tiene una mayor utilidad para el diagnóstico de infección primaria y estudios epidemiológicos(11). Los resultados obtenidos para la IgG nos permiten inferir que la infección activa diagnosticada a través de las técnicas moleculares fueron consecuencia de un proceso de reactivación viral.

En cuanto al test de Tzanck, los pacientes 2, 4 y 6 mostraron cambios morfológico intranucleares e intracitoplasmáticos como células gigantes multinucleadas, que forman sincitios en forma de globo, núcleos megaloblásticos e inclusiones intranucleares e intracitoplasmáticas por virus, lo que confirma actividad viral, y se ha descrito específicamente para HHV-6(12). Sin embargo, esta técnica tiene una baja sensibilidad $(60-70 \%)^{(13)}$, lo que se considera una técnica complementario al diagnóstico de la familia herpesviridae(14).

Dentro de las manifestaciones dermatológicas más usuales en los 6 casos reportados están: exantema, roséola, vesículas, nevus rubí e hiperqueratosis, las cuales se han relacionado con la actividad del HHV-6 en diversos estudios(3). En la revisión realizada por Wolz et al., reportan que lesiones cutáneas clasificadas en exantema súbito, pitiriasis rosada, liquen plano, púrpura trombocitopénica idiopática, púrpura fulminante, alergia a medicamentos, síndrome de Stevens-Johnson y Gianotti-Crosti, están altamente relacionadas a la reactivación viral por HHV-6 y HHV-7(3).

Estudios han demostrado una mayor replicación activa del HHV-6 en cultivos primarios de linfocitos de pacientes con Síndrome de Fatiga Crónica vs. personas sanas, demostrando una asociación fuerte entre ambas entidades(15). Las manifestaciones neurológicas atribuidas a la presencia del HHV-6 como pérdida de concentración, alteraciones en la memoria, decaimiento y depresión, estuvieron presentes en los casos reportados en este artículo, y se corresponde con lo reportado por Blomberg et al., en pacientes con HHV-6 que presentaron fatiga crónica(16). De manera adicional a la descripción anterior, otros autores han considerado pertinente clasificar dentro del síndrome de fatiga crónica, la presencia de dolor fibromuscular, poliarticular, malestar pos esfuerzo y sueño no reparador(17), síntomas que estuvieron presentes en la totalidad de casos presentados y que se han correlacionado con una infección activa por el virus HHV-6.

Debido a que el HHV-6 produce amplias manifestaciones clínicas similares con otras enfermedades de mayor frecuencia, el diagnóstico de esta entidad ha sido relegado y muy frecuentemente confundido, llevando a un diagnóstico y manejo errado. Adicionalmente, las estadísticas nacionales y departamentales respecto a la epidemiologia de este agente etiológico son desconocidas, y si bien existen métodos de diagnóstico descritos en la literatura mundial, a nivel nacional aún no se han implementado.

\section{Conclusiones}

A través de esta serie de casos se espera sensibilizar a la comunidad médica sobre el papel que juega el HHV-6 en la evolución de diversas patologías, al mismo tiempo que resalta la importancia de la identificación de la infección activa del virus a través de métodos moleculares.

En los pacientes reportados en esta serie de casos, los cuales fueron diagnosticados con infección activa por HHV-6, la fatiga crónica; las afecciones neurológicas como depresión, decaimiento, pérdida de memoria y de concentración; las lesiones dermatológicas como liquen plano y lesiones hipo e hiperpigmentadas, fueron condiciones comunes entre los pacientes. 


\section{Conflicto de intereses}

Los autores declaran no tener conflictos de interés.

\section{Agradecimientos}

A la Vicerrectoría de Investigaciones de la Universidad del Cauca por la financiación, al Grupo de Investigación en Inmunología y Enfermedades Infecciosas y al Semillero en Inmunología y Enfermedades, por brindarnos el conocimiento necesario para realizar el presente escrito. A nuestros pacientes por permitirnos estudiar sus casos.

\section{Referencias}

1. Agut $\mathrm{H}$, Bonnafous $\mathrm{P}$, Gautheret-Dejean A. Laboratory and clinical aspects of human herpesvirus 6 infections. Clinical microbiology reviews. 2015;28(2):313-335.

2. Pellett PE, Ablashi DV, Ambros PF, et al. Chromosomally integrated human herpesvirus 6: questions and answers. Reviews in medical virology. 2012;22(3):144-155.

3. Wolz MM, Sciallis GF, Pittelkow MR. Human herpesviruses 6, 7, and 8 from a dermatologic perspective. Mayo Clinic Proceedings: Elsevier. 2012:1004-1014.

4. Caselli E, Soffritti I, D’Accolti M, et al. HHV-6A Infection and Systemic Sclerosis: Clues of a Possible Association. Microorganisms. 2020;8(1):39.

5. Bartolini $\mathrm{L}$, Theodore $\mathrm{WH}$, Jacobson $\mathrm{S}$, et al. Infection with HHV-6 and its role in epilepsy. Epilepsy research. 2019;153:34-39.

6. Shikova E, Reshkova V, Kumanova A, et al. Cytomegalovirus, Epstein-Barr virus, and human herpesvirus-6 infections in patients with myalgic encephalomyelitis/chronic fatigue syndrome. Journal of Medical Virology. 2020.

7. Gautheret-Dejean A, Agut H. Practical diagnostic procedures for HHV-A, HHV-6B, and HHV-7. Human herpesviruses
HHV-6A, HHV-6B \& HHV-7, 3rd ed Elsevier, Amsterdam, Netherlands. 2014:9-34.

8. Caserta MT, Hall CB, Schnabel K, et al. Diagnostic assays for active infection with human herpesvirus 6 (HHV-6). Journal of Clinical Virology. 2010;48(1):55-57.

9. Xing J, Xiao Ye, Tang X, et al. Inhibition of Cyclosporine A or rapamycin on $T$ lymphocyte counts and the influence on the immune responses of $B$ lymphocytes in flounder (Paralichthys olivaceus). Fish \& shellfish immunology. 2017;66:78-85.

10. Sutherland S, Christofinis G, O'Grady J, et al. A serological investigation of human herpesvirus 6 infections in liver transplant recipients and the detection of cross-reacting antibodies to cytomegalovirus. Journal of Medical Virology. 1991;33(3):172-176.

11. Agut $\mathrm{H}$, Bonnafous $\mathrm{P}$, Gautheret-Dejean A. Update on infections with human herpesviruses $6 \mathrm{~A}, 6 \mathrm{~B}$, and 7 . Médecine et Maladies Infectieuses. 2017;47(2):83-91.

12. Becerra-Artiles A, Santoro T, Stern LJ. Evaluation of a method to measure HHV-6B infection in vitro based on cell size. Virology journal. 2018;15(1):4.

13. Marcano-Lozada M, Serrano N, Urrestarazu MI. El Test de Tzanck como herramienta diagnóstica en lesiones de piel. Estudio preliminar. Revista de la Sociedad Venezolana de Microbiología. 2006;26(1):305-310.

14. Rocher A, Angeleri A, Rofrano J, et al. Revaluing the Tzanck Test: A Comparative Study with Direct Immunofluorescence for Herpes Virus. Journal of Advances in Medicine and Medical Research. 2016:1-7.

15. Underhill R. Myalgic encephalomyelitis, chronic fatigue syndrome: an infectious disease. Medical hypotheses. 2015;85(6):765-773.

16. Blomberg J, Rizwan M, Böhlin-Wiener A, et al. Antibodies to Human Herpesviruses in Myalgic Encephalomyelitis/Chronic Fatigue Syndrome Patients. Frontiers in Immunology. 2019;10:1946.

17. Larun L, Brurberg KG, Odgaard-Jensen J, et al. Exercise therapy for chronic fatigue syndrome. Cochrane database of systematic reviews. 